\title{
Tumor de células epitelioides perivasculares (PECOMA) hepático: relato de caso
}

\section{Perivascular epithelioid cell tumor (PECOMA) hepatic: case report}

Tamises Melo Siqueira Marinhoํ. José Telmo Valença Júnior ${ }^{1,2}$. Gabriela Maia Coelhoํ․ Sami de Andrade Cordeiro Gadelha ${ }^{1}$.

1 Universidade Federal do Ceará (UFC), Fortaleza, Ceará, Brasil. 2 Empresa Brasileira de Serviços Hospitalares (EBSERH), laboratório Mikros, Fortaleza, Ceará, Brasil.

\section{RESUMO}

Relata-se um caso de tumor de células epitelioides perivasculares (PECOMA) hepático, diagnosticado em paciente feminino no Hospital Universitário Walter Cantídio. Inicialmente, foi feita revisão de prontuário e em seguida, iniciou-se pesquisa bibliográfica da literatura nacional e internacional, obtidos nas bases de dados: SciELO e MEDLINE. PEComas são tumores raros, caracterizados pela coexpressão de fatores de transcrição melanocíticos e musculares. O caso de uma paciente de 49 anos com crises recorrentes de dor e desconforto epigástrico após alimentação. Tomografia computadorizada de abdome revelou volumosa massa hepática heterogênea, predominantemente hipodensa, de contornos regulares e limites definidos, exibindo áreas de necrose e artérias calibrosas internas serpinginosas e radiais, incluindo dilatações aneurismáticas. Paciente foi submetida à hepatectomia parcial. Macroscopicamente, os cortes de segmentos hepáticos exibiam tumoração bem delimitada, medindo $15,0 \mathrm{~cm}$, pardoamarronzada, com aspecto necrótico. À microscopia, o tumor era composto de células epitelioides poligonais, positivas para marcadores melanocíticos à imuno-histoquímica. Conclusões: PEcomas são tumores raros, que podem surgir em diversas regiões e são categorizados em benignos, com potencial maligno incerto ou malignos. Apresentamos o caso de uma paciente, que após exérese da lesão, evoluiu clinicamente estável, sem recorrência da doença, após seis meses de seguimento.

Palavras-chave: Neoplasias de Células Epitelioides Perivasculares. Fígado. Diagnóstico.

\section{ABSTRACT}

We report a case of hepatic perivascular epithelioid cell tumor (PECOMA) diagnosed in a female patient at Walter Cantídio University Hospital. Initially, a medical record was reviewed and then a bibliographic search of the national and international literature was obtained, obtained from the databases: SciELO and MEDLINE. PEComas are rare tumors, characterized by the coexpression of melanocytic and muscular transcription factors. The case of a 49-year-old woman with recurrent bouts of pain and epigastric discomfort after feeding. Computed tomography of the abdomen revealed a large, predominantly hypodense, heterogeneous hepatic mass with regular contours and defined limits, showing areas of necrosis and internal calypsoar arteries, including radial and aneurysmal dilatations. Patient was submitted to partial hepatectomy. Macroscopically, the hepatic segments showed a well-defined tumor, measuring $15.0 \mathrm{~cm}$, brownish-brown, with a necrotic appearance. Under microscopy, the tumor was composed of polygonal epithelioid cells, positive for melanocytic markers to immunohistochemistry. Conclusions: PE tumors are rare tumors, which may arise in several regions and are categorized as benign, with uncertain or malignant potential. We report the case of a patient who, after excision of the lesion, developed a clinically stable condition without recurrence after six months of follow-up.

Keywords: Perivascular Epithelioid Cell Neoplasm. Liver. Diagnosis.

Autor correspondente: Tamises Melo Siqueira Marinho, Avenida Luciano Carneiro, 635, Fátima, Fortaleza, Ceará, Brasil. CEP: 60411-205. Telefone: +5588 99953-3789. E-mail: tamisesmelo@yahoo.com.br

Conflito de interesses: Não há qualquer conflito de interesses por parte de qualquer um dos autores.

Recebido em: 17 Jul 2019; Revisado em: 21 Out 2019; Aceito em: 14 Nov 2019. 


\section{INTRODUÇÃO}

Os tumores de células epitelioides perivasculares (PEComas) são uma família de tumores raros, definidos pela Organização Mundial de Saúde, como "tumores mesenquimais compostos de células epitelioides perivasculares histológica e imunohistoquimicamente distintas.

Historicamente, neoplasias de células epitelioides perivasculares (PEcomas) foram descritas, pela primeira vez, por Bonetti et al. em 1992. ${ }^{2}$ Dez anos depois, em 2002, os PEComas foram reconhecidos como entidades independentes de acordo com a Organização Mundial de Saúde. ${ }^{3}$ Dentro da família dos PEComas estão incluídos: angiomiolipoma renal e extra renal, tumor de células claras do pulmão e extrapulmonar, linfangioleiomiomatose, tumor de células claras miomelanocíticas do ligamento falciforme e neoplasias classificadas como PEComa sem outra especificação. Os PEComas são tumores muito raros em outras localizações anatômicas que não o rim e o pulmão, entretanto foram descritos casos em: cólon, pâncreas, retroperitônio, coração, glândula adrenal, mama, olho, ducto biliar, osso, bexiga, base do crânio, colo do útero, pele, nasofaringe e fígado. ${ }^{4}$

Possuem características morfológicas, imuno-histoquímicas, ultraestruturais e genéticas distintas; e são caracterizados por localização tipicamente perivascular, com atipia leve ou ausente. Imuno-histoquimicamente, eles expressam marcadores miogênicos e melanocíticos, como HBM-45, antígeno-1 humano associado ao melanossomo (HMSA-1), antígeno de melanoma reconhecido pelas células T (Melan-A ou Mart-1), fator de transcrição associado à microftalmia (Mitf), actina e desmina. ${ }^{5}$

\section{RELATO DE CASO}

Paciente, feminina, 60 anos, iniciou há um ano crises recorrentes de desconforto epigástrico após alimentação. Procurou assistência médica sendo realizada ultrassonografia abdominal e ressonância nuclear magnética que evidenciou tumoração em lobo hepático direito. Paciente foi encaminhada para acompanhamento no Hospital Universitário Walter Cantídio, onde realizou tomografia computadorizada multislice de abdome, que demonstrou volumosa lesão expansiva globosa hepática, de contornos definidos, medindo $19,0 \times 14,0 \mathrm{~cm}$, apresentando densidade heterogeneamente reduzida em relação ao parênquima adjacente e exibindo moderado realce irregular com abundante vascularização e algumas pequenas áreas hipocaptantes compatíveis com necrose/liquefação lobulados, definindo-se fina cápsula contínua. Além de pronunciado efeito de massa pela lesão, deslocando centrifugamente as estruturas circunjacentes, comprimindo vias biliares e ramos portais intra-hepáticos, destacando-se afilamento extremo do segmento intra-hepático da veia cava inferior (Figura 1).

Macroscopicamente, o produto de hepatectomia parcial apresentava tumoração, bem delimitada, medindo 15,0 x 12,0 x $11,0 \mathrm{~cm}$, pardo-amarronzada com áreas de aspecto necrótico em aproximadamente $95 \%$ de sua superfície (Figura 2).
À microscopia, os cortes histológicos mostravam neoplasia formada por células epitelioides, poligonais, de núcleos moderadamente pleomórficos e vesiculosos permeados por vasos de calibres variados e ectásicos. Grandes áreas de necrose, porém não apresentou figuras de mitose. $\mathrm{O}$ parênquima adjacente apresentava septos fibrosos.

Foi realizado estudo imuno-histoquímico que mostrou positividade nas células neoplásicas para vimentina e marcadores melanocíticos como Melan A e HMB45 e negatividade para marcadores hepáticos como HepPar-1 (Figura 3).

A paciente foi seguida clinicamente e não foram evidenciados sinais de recorrência da doença até então, após seis meses de seguimento.

Figura 1. Tomografia computadorizada no plano axial, fases sem contraste (A), arterial (B), portal (C) e tardia (D) e reconstrução no plano coronal MIP (E). Volumosa massa hepática heterogênea, predominantemente hipodensa, hipovascular, de contornos regulares e limites definidos, exibindo áreas de necrose e artérias calibrosas internas serpinginosas e radiais, incluindo dilatações aneurismáticas.

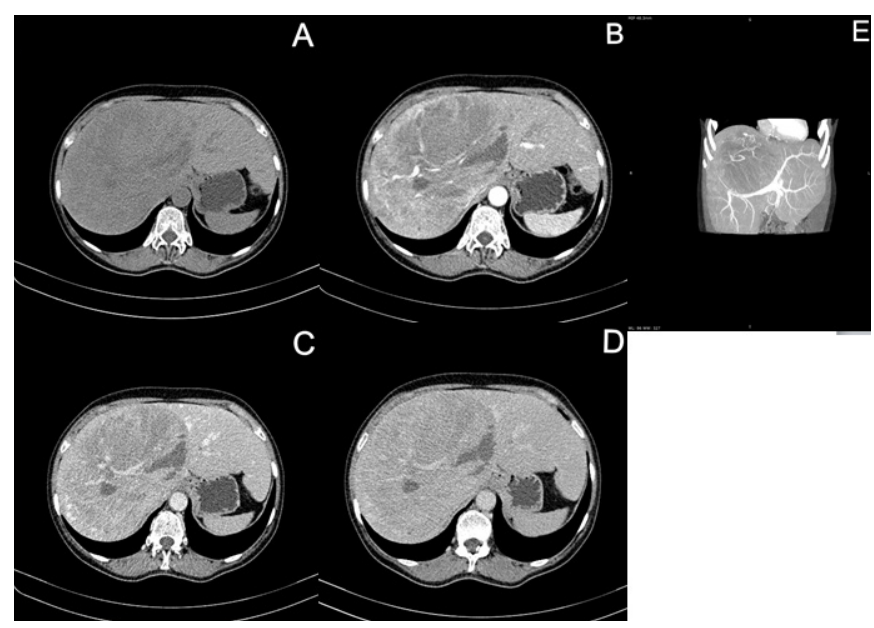

Figura 2. Peça de hepatectomia parcial seccionada transversalmente mostrando tumor pardo-amarronzado com áreas de aspecto necrótico (enegrecidas).

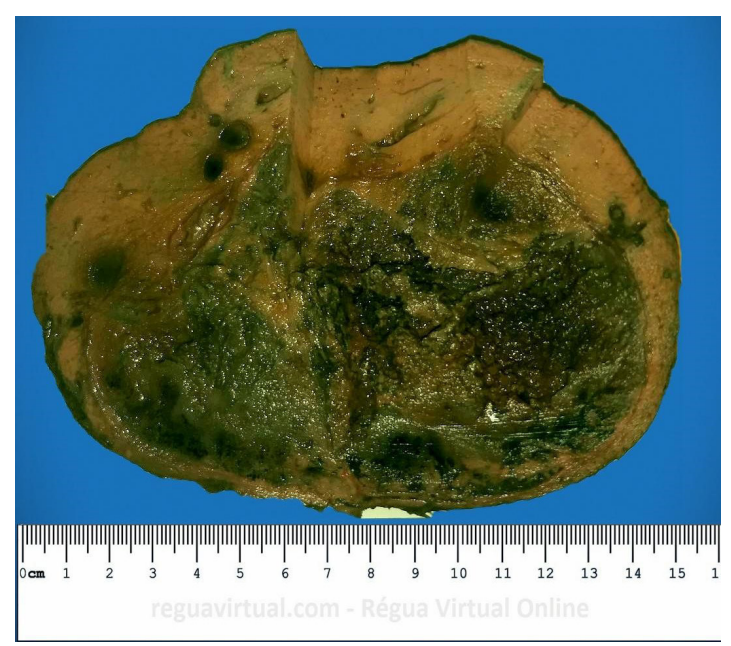


Figura 3. Microfotografia exibindo em (A) neoplasia permeada por vasos ectásicos de diferentes calibres (40x); (B) Células neoplásicas poligonais com depósitos eosinofílicos (200x); (C) células epitelioide com núcleos vesiculosos com moderado pelomorfismos (400x). Imuno-histoquímica: (D) Imunoexpressão de melanA nas células neoplásicas; (E) Imunonegatividade de HepPar-1 (F) Imunoexpressão de HMB-45 nas células neoplásicas.

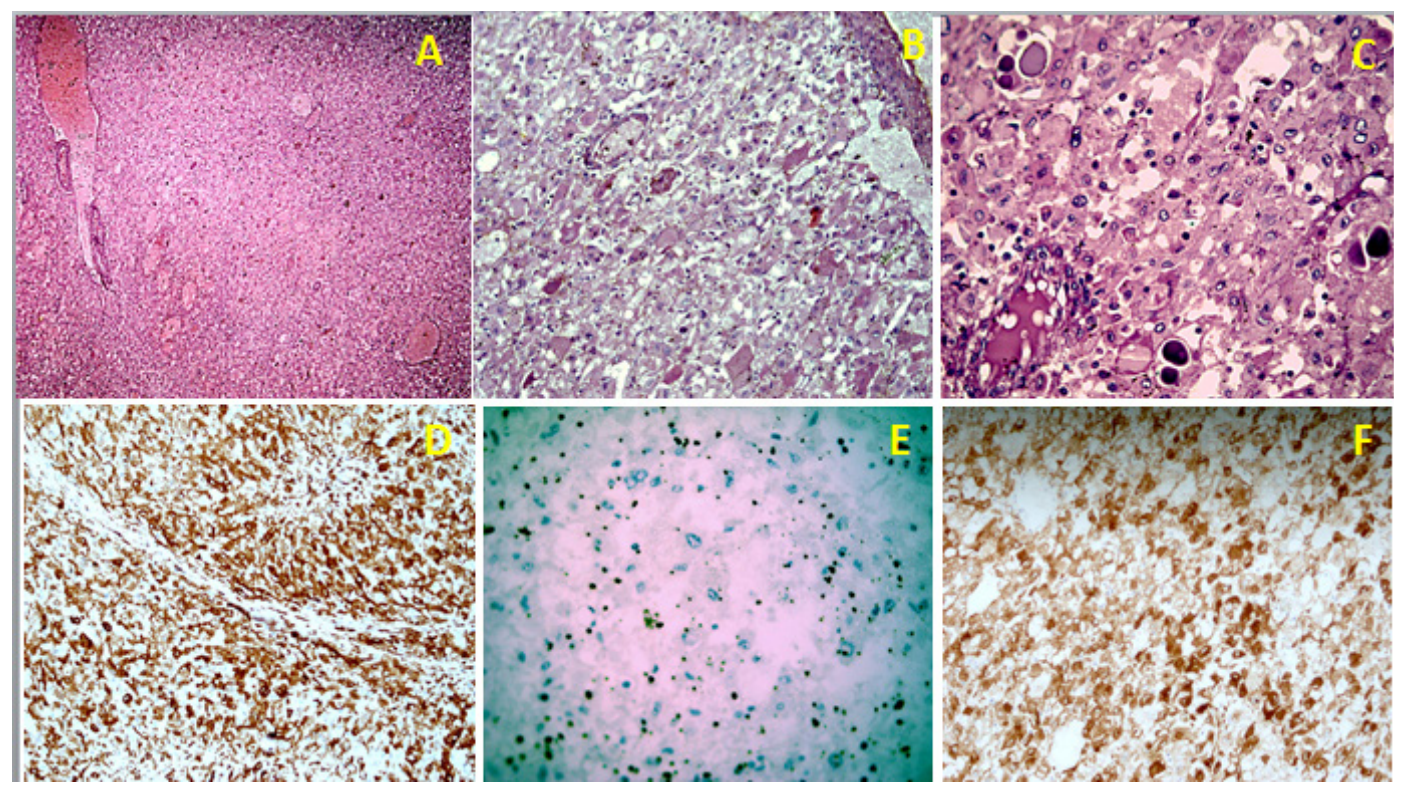

\section{DISCUSSÃO}

O termo "PEComa" abrange numerosos tipos tumorais raros, histologicamente diversos, que podem ocorrer em quase todos os órgãos com predomínio de órgãos pélvicos. ${ }^{6}$ Podem ocorrer em extremos de idade, com média de idade de 43 anos, em estudos de revisão, e forte predominância feminina tem sido um achado consistente. ${ }^{7}$ Os PEComas hepáticos são muito raros; ocorrem principalmente em adultos, com ampla faixa etária (10-86 anos) e mantém a predominância do sexo feminino (relação femininomasculino, de 2:1 a 5:1). A maioria dos pacientes é assintomática ou apresenta sintomas gastrointestinais inespecíficos; os tumores são encontrados incidentalmente. Lesões grandes causam dor epigástrica e, raramente, a ruptura com o hemoperitônio ocorre em grandes tumores subcapsulares. ${ }^{8}$

A morfologia epitelioide das células tumorais e o padrão trabecular podem favorecer erroneamente o diagnóstico de Carcinoma Hepatocelular. A observação de grandes células claras ou com condensação eosinofílica ao redor do núcleo, alerta os patologistas para a possibilidade do diagnóstico de PEComa. ${ }^{8}$ Para confirmação, deve ser realizado estudo imunohistoquímicos com HMB45 e/ou Melan A. No presente caso, as células tumorais foram imunorreativas de maneira forte $\mathrm{e}$ difusa para HMB45 e Melan A e negativas para o marcador hepatocitário HepPar-1.

A maioria dos autores concorda que os critérios para malignidade e o comportamento biológico dos PEComas não foram suficientemente estabelecidos. Isso pode ser parcialmente atribuível à escassez de casos relatados, à heterogeneidade histológica das células tumorais, à variabilidade na nomenclatura e as especificidades do órgão de origem. Embora a maioria dos PEComas relatados se comportem de maneira benigna, uma minoria destaca-se por demonstrar comportamento maligno com recidiva localmente destrutiva e metástase à distância. Os critérios para malignidade em PEComas de origem de tecidos moles e ginecológicos são determinados por atividade mitótica, necrose, atipia nuclear acentuada e pleomorfismo. Folpe et al. propuseram uma categorização provisória de PEComas em benigno, potencial maligno incerto (PMI), e neoplasia maligna. ${ }^{9}$ As características não preocupantes (menos de 5,0 cm de tamanho, não infiltrativa, baixo a moderado grau nuclear e celularidade, atividade mitótica menor que 1/50 campos de grande aumento (CGA), sem necrose coagulativa ou invasão vascular) são identificados em espécimes ressecados e categorizados como benignos. Os tumores da PMI apresentavam apenas pleomorfismo nuclear/ células gigantes multinucleadas ou tamanho do tumor maior que $5,0 \mathrm{~cm}$. Tumores com dois ou mais aspectos preocupantes se classificam em malignos. Esses critérios foram aplicados em vários casos relatados subsequentemente, embora o papel desses em orientar o gerenciamento do tratamento ainda não esteja claro.?

Embora não se enquadre em tumores de partes moles ou ginecológicos; ao aplicamos os critérios, nosso caso mostrou duas das características preocupantes acima. São elas: o tamanho maior que 5,0 cm e, a extensa necrose. Porém, em acompanhamento, a paciente mostrou bom estado geral e não recidiva da doença em 6 meses.

Em conclusão, PEComa são tumores raros, que podem apresentar características benignas e malignas. Apresentamos um caso de PEComa hepático primário com provável potencial de malignidade em uma mulher de 60 anos de idade, inspecionamos a natureza deste tumor e destacamos a necessidade de ampla investigação para a estratificação do comportamento biológico de PEComas. A ressecção é a opção de tratamento de escolha para casos ressecáveis. 


\section{REFERÊNCIAS}

1. Folpe AL. Neoplasms with perivascular epithelioid cell differentiation (PEComas). In: Fletcher CD, Unni KK, Mertens F, eds. World Health Organization Classification of Tumors: pathology and genetics of tumors of soft tissue and bone. Lyon: IARC Press; 2002. p. 221-222.

2. Bonetti F, Pea M, Martignoni G, Zamboni G. PEC and Sugar. Am J Surg Pathol. 1992;16(3):307-8.

3. Fletcher C, Unni KK, Mertens F. Pathology and genetics of tumours of soft tissue and bone. Lyon: IARC Press; 2002.

4. Tortosa SO. Angiomiolipoma epitelioide hepático: correlación clínico-patológica en una serie de 4 casos. Rev Esp Enferm Dig. 2016;108(1):27-30.

5. Martignoni G, Pea M, Reghellin D, Zamboni G, Bonetti F. PEComas: the past, the present and the future. Virchows Arch. 2008;452(2):119-32.
6. Kirste S, Kayser G, Zipfel A, Grosu AL, Brunner T. Unresectable hepatic PEComa: a rare malignancy treated with stereotactic body radiation therapy (SBRT) followed by complete resection. Radiat Oncol. 2018;13(1):28.

7. Bleeker JS, Quevedo JF, Folpe AL. "Malignant" perivascular epithelioid cell neoplasm: risk stratification and treatment strategies. Sarcoma. 2012;2012(541626):1-12.

8. Son HJ, Kang DW, Kim JH, Han HY, Lee MK. Hepatic perivascular epithelioid cell tumor (PEComa): a case report with a review of literatures. Clin Mol Hepatol. 2017;23(1):80-6.

9. Folpe AL, Mentzel T, Lehr HA, Fisher C, Balzer BL, Weiss SW. Perivascular epithelioid cell neoplasms of soft tissue and gynecologic origin: a clinicopathologic study of 26 cases and review of the literature. Am J Surg Pathol. 2005;29(12):1558-75.

\section{Como citar:}

Marinho TM, Valença JT Júnior, Coelho GM, Gadelha SA. Tumor de células epitelioides perivasculares (PECOMA) hepático: relato de caso. Rev Med UFC. 2020 abr-jun;60(2):51-54. 